\title{
Panobinostat PK/PD profile in combination with bortezomib and dexamethasone in patients with relapsed and relapsed/refractory multiple myeloma
}

\author{
Song $\mathrm{Mu}^{1}$ • Yoshiaki Kuroda ${ }^{2} \cdot$ Hirohiko Shibayama $^{3}$ - Masayuki Hino ${ }^{4}$. \\ Takeshi Tajima $^{5} \cdot$ Claudia Corrado $^{6} \cdot$ Rong Lin $^{1} \cdot$ Edward Waldron $^{1} \cdot$ \\ Florence Binlich $^{7} \cdot$ Kenshi Suzuki $^{8}$
}

Received: 25 August 2015 / Accepted: 14 October 2015 /Published online: 22 October 2015

(C) The Author(s) 2015. This article is published with open access at Springerlink.com

\begin{abstract}
Purpose Panobinostat, a potent pan-deacetylase inhibitor, improved progression-free survival (PFS) in patients with relapsed and refractory multiple myeloma when combined with bortezomib and dexamethasone in a phase 3 trial, PANORAMA-1. This study aims to explore exposure-response relationship for panobinostat in this combination in a phase 1 trial, B2207 and contrast with data from historical single-agent studies.

Methods Panobinostat plasma concentration-time profiles were obtained in patients from PANORAMA-1 $(n=12)$ and B2207 $(n=12)$ trials. Overall response rates (ORR) and major adverse events (AE) by panobinostat exposure were investigated in the B2207 trial. Panobinostat PK data from combination trials were contrasted with data from single-agent studies. Results At maximum tolerated dose (MTD), the geometric mean of panobinostat area under curve from 0 to $24 \mathrm{~h}$
\end{abstract}

Information on clinical trials The data presented in this manuscript are from the following 2 clinical trials: PANORAMA-1 and B2207. Both the trials are registered at ClinicalTrials.gov with the following identifier numbers: NCT01023308 (for PANORAMA-1) and NCT00532389 (for B2207).

Song $\mathrm{Mu}$

song.mu@novartis.com

Novartis Pharmaceuticals Corporation, East Hanover, NJ, USA

Hiroshima University Hospital, Hiroshima, Japan

Osaka University Graduate School of Medicine, Osaka, Japan

Osaka City University Hospital, Osaka, Japan

Novartis Pharma KK, Tokyo, Japan

Novartis Pharma AG, Basel, Switzerland

Novartis Pharma S.A.S, Rueil-Malmaison, France

8 Japanese Red Cross Medical Center, Tokyo, Japan
(AUC0-24) was $47.5 \mathrm{ng} \mathrm{h/mL} \mathrm{(77 \%} \mathrm{CV),} \mathrm{and} \mathrm{maximum}$ plasma concentration (Cmax) was $8.1 \mathrm{ng} / \mathrm{mL}(90 \% \mathrm{CV})$. These values were comparable with exposure data obtained in PANORAMA-1, but were $20 \%$ lower than those without dexamethasone, and $50 \%$ lower from single-agent trials, likely due to enzyme induction by dexamethasone. Higher levels of panobinostat exposure were associated with higher response rates and higher incidences of diarrhea and thrombocytopenia.

Conclusions Apparent panobinostat exposure-AE and exposure-ORR relationships were observed when combined with bortezomib and dexamethasone in the treatment of patients with relapsed and refractory multiple myeloma. The addition of dexamethasone facilitated best response even though plasma exposure of panobinostat was reduced. Combination with a strong enzyme inducer should be avoided in future trials to prevent further reduction of panobinostat exposure.

Keywords Panobinostat - Histone deacetylase inhibitor . Clinical trials $\cdot$ Pharmacokinetics $\cdot$ Pharmacodynamics

\section{Introduction}

Panobinostat is a pan-histone deacetylase inhibitor (HDACi) with low nanomolar activity against class I, II, and IV histone deacetylases $[1,2]$. Panobinostat $\left(\right.$ Farydak $\left.^{\circledR}\right)$ in combination with bortezomib and dexamethasone was recently approved in the USA, European Union, and Japan, for treatment of relapsed or relapsed and refractory multiple myeloma, in patients who had received at least 2 prior regimens, including bortezomib and an immunomodulatory agent. The anticancer activity of panobinostat is thought to be due to its effect on epigenetic modulation and inhibition of proteolytic 
degradation pathways $[3,4]$. Panobinostat showed synergistic antimyeloma activity when combined with the proteasome inhibitor, bortezomib, in cell lines in vitro [5, 6], and more recently, this combination showed a clinically relevant extension in progression-free survival in a phase 3 clinical trial (PANORAMA-1), in patients with relapsed and relapsed/ refractory multiple myeloma [7]. Previously, an open-label, phase $1 \mathrm{~b}$ trial (B2207), with escalating doses of panobinostat and bortezomib with or without dexamethasone, was carried out in order to determine the maximum tolerated dose (MTD) and recommended dose for this combination [8]. Both the trials provided data on panobinostat exposure in combination with dexamethasone and bortezomib.

The safety and pharmacokinetic (PK) profile of singleagent panobinostat have been studied in multiple phase 1 and 2 trials [9-12]. Drug metabolism and distribution have been characterized using trace radiolabeled panobinostat [10]. Other studies addressed changes in panobinostat PK or safety in patients with impaired hepatic or renal function [13, 14], interactions of panobinostat with a sensitive CYP2D6 substrate, a strong CYP3A inhibitor, and effect of food on panobinostat disposition [15-17].

The objective of the current study is to characterize the PK of panobinostat in the combination regimen with dexamethasone and bortezomib (PANORAMA-1 and B2207 clinical trials $[7,8]$ ), in comparison with the PK profile of the single agent. The relationship of panobinostat exposures to overall response rate (ORR) per International Myeloma Working Group (IMWG) criteria and frequency of occurrence of grade 3 or 4 adverse events (AEs) in the phase $1 \mathrm{~b}$ trial B2207 were also analyzed.

\section{Clinical pharmacology of single-agent panobinostat}

Panobinostat is rapidly absorbed following oral administration with a median time (Tmax) to reach maximum plasma concentration $(\mathrm{Cmax})$ of about $2 \mathrm{~h}$. Mean concentration-time profiles after a $20 \mathrm{mg} / \mathrm{m}^{2}$ iv or $20 \mathrm{mg}$ oral administration can be found in Fig. 1 [10]. The effective half-life (T1/2) of panobinostat is approximately $16 \mathrm{~h}$ based on the rate of accumulation of approximately 1.1-fold observed in single-agent trial [10], and steady state is reached after the third dose in a thrice-weekly (tiw) dosing schedule [10]. It is extensively metabolized through both CYP and non-CYP mediated pathways; the fraction of the radiolabeled dose recovered in the feces and urine was 44 to $77 \%$ and 29 to $51 \%$, respectively [10]. Unchanged panobinostat in the feces accounted for $<3.5 \%$ of the administered dose, suggesting good oral absorption [10]. Pharmacokinetics of panobinostat is approximately linear in the tested dose range between 10 and $30 \mathrm{mg}$. The oral bioavailability of panobinostat is marginally affected by fed or fasting state of the patient, and the food effect is not considered clinically relevant [17].
Panobinostat is biotransformed into over 70 metabolites, none of which showed pharmacologic activity at concentrations of up to $30 \mu \mathrm{M}$ [10]. Panobinostat shows a weak drugdrug interaction potential. Ketoconazole, a strong CYP3A inhibitor, increased the systemic exposure of panobinostat by $80 \%$ in cancer patients [16]. Panobinostat increased the systemic exposure of a sensitive CYP2D6 substrate, dextromethorphan by $60 \%$, in cancer patients [15]. Mild, moderate, or severe renal impairment did not alter the plasma exposure of panobinostat in patients with solid tumors [14]; however, mild and moderate hepatic impairment increased panobinostat exposure by 43 and $105 \%$, respectively [13].

\section{Methods}

Multiple clinical trials with panobinostat PK are compared in the current analysis. All patients in the trials gave written informed consent for participation, and the study protocols were approved by the institutional review board/independent ethics committee/research ethics board at each study site. The clinical trials PANORAMA-1 [7] and B2207 [8] are registered at ClinicalTrials.gov with the identifier numbers NCT01023308 and NCT00532389, respectively. A detailed description of the study design and key results for panobinostat single-agent trials are available in the published literature $[9,11,12,18]$.

\section{Study design}

\section{B2207 clinical trial}

This was an open-label, phase $1 \mathrm{~b}$ study done in 2 phases: a dose-escalation phase (using 10-30 mg oral panobinostat and 1 or $1.3 \mathrm{mg} / \mathrm{m}^{2}$ intravenous [IV] bortezomib) to determine MTD and a dose-expansion phase at MTD to determine safety and efficacy. The MTD was $20 \mathrm{mg}$ tiw panobinostat and $1.3 \mathrm{mg} / \mathrm{m}^{2}$ twice-weekly (biw) bortezomib. In the doseexpansion phase, patients were treated at MTD for eight, 3week cycles ( 2 weeks of panobinostat and bortezomib therapy and 1 week with no drugs). In addition, 20-mg oral dexamethasone was added starting cycle 2 on the day of and the day after bortezomib therapy. After 8 cycles, patients could discontinue bortezomib/dexamethasone and continue on panobinostat alone until disease progression or discontinuation.

\section{PANORAMA-1 clinical trial}

This was a phase 3 , randomized, double-blind, placebocontrolled trial that assessed efficacy of panobinostat versus placebo plus bortezomib and dexamethasone at the MTD dose and schedule, determined in B2207 trial, 
Fig. 1 Plasma concentrationtime profiles of panobinostat following a single $20 \mathrm{mg} / \mathrm{m}^{2}$ IV dose and a single $20 \mathrm{mg}$ oral dose

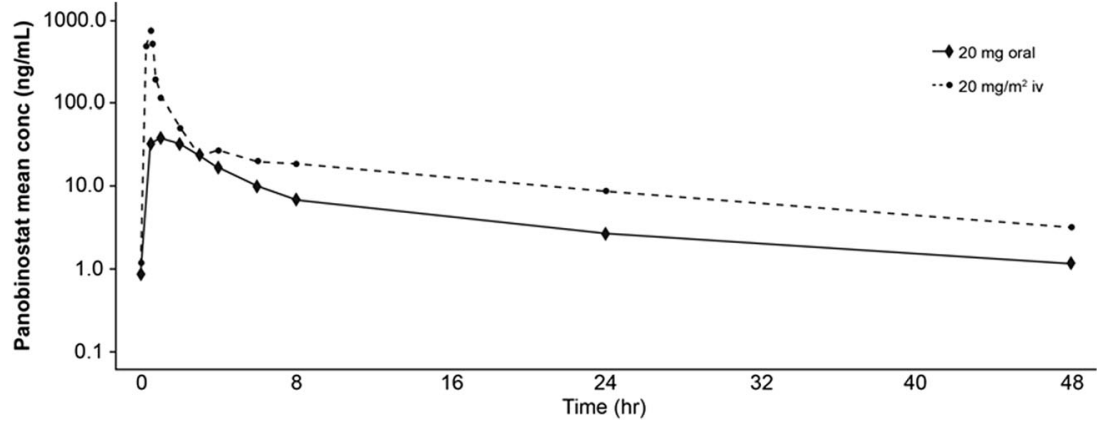

in 2 treatment phases. Each phase was of 24 weeks duration with treatment phase 1 consisting of eight, 3week cycles and treatment phase 2 consisting of four, 6week cycles. Those patients who had received clinical benefit in treatment phase 1 could proceed to treatment phase 2, in which the bortezomib dose schedule was dropped to once weekly (qw) instead of biw.

\section{PK assessment}

\section{B2207 trial}

PK assessment was carried out in the dose escalation and dose expansion parts of the trial for both panobinostat and bortezomib. In the dose escalation part, PK samples were collected on cycle 1, day 8, and cycle 1 , day 15 at pre-dose, and various intervals post-dose up to $48 \mathrm{~h}$. In the dose expansion part, an initial PK sampling was done on cycle 1 day 8 to obtain PK data for panobinostat and bortezomib in the absence of dexamethasone. Subsequent PK sampling was done on cycle 2 , day 8 to obtain PK data for panobinostat and bortezomib in the presence of dexamethasone. Concentration-time profiles of dexamethasone were not assessed. Blood samples were taken at pre-dose (for both drugs): at 5 and $15 \mathrm{~min}$ (for bortezomib alone) and at 0.5, 1, 2, 3, 4, 6, 8, 24, and $48 \mathrm{~h}$ post-dose (for both drugs). Plasma panobinostat concentrations were measured using a validated liquid chromatography tandem mass spectrometry (LC-MS/ MS) method with lower limit of quantification (LLOQ) of $0.1 \mathrm{ng} / \mathrm{mL}[10,19]$.

\section{PANORAMA-1 trial}

In this study, plasma samples for panobinostat and bortezomib were collected in a subset of Asian patients. Blood samples were taken at scheduled time points (cycle 1 , day 1 , and cycle 1 day 8 at pre-dose and at 0.5 , $1,2,3,4,8,24$, and $48 \mathrm{~h}$ post-dose) for PK analysis.

\section{Pharmacokinetic analysis}

Pharmacokinetic analyses were conducted in WinNonlin Pro version 5.2 (Pharsight, Gary, NC) to derive PK parameters such as Cmax and Tmax for panobinostat and bortezomib, total body clearance $(\mathrm{CL} / \mathrm{F})$, apparent volume of distribution $(\mathrm{Vz} / \mathrm{F})$, area under the curve from time zero to $24 \mathrm{~h}$ (AUC024 ), area under the curve from time zero to infinity (AUC0inf), and terminal half-life (T1/2).

\section{Efficacy and safety assessment}

The two combination studies, B2207 and PANORAMA-1, reported efficacy data in patients with relapsed and refractory multiple myeloma [7, 8]. In the current analysis, exposureefficacy relationship was explored using the efficacy data (ORR based on IMWG criteria) from the B2207 trial. Exposure-safety relationship was also characterized for the dose ranges of 10 to $30 \mathrm{mg}$ panobinostat and 1 or $1.3 \mathrm{mg} / \mathrm{m}^{2}$ bortezomib in the B2207 trial.

\section{Results}

The baseline demographic data for the subset of patients with PK information from PANORAMA-1 and B2207 clinical trials are summarized in Table 1 . The median age for patients in the PANORAMA-1 trial was 63 years and for patients in the B2207 was 62 years. The B2207 trial had 19 centers in Australia, Europe, and North America [8], and the PANORAMA1 study had 215 centers in 34 countries, including Japan [7]. The PK data for PANORAMA-1 study were provided only from centers in Japan. Both trials enrolled patients with a median of 2 prior therapies, and $\geq 50 \%$ of patients had bortezomib in their prior line of therapy.

\section{Dexamethasone effect on panobinostat exposures}

B2207 study used escalating doses of panobinostat (10, 20, 25 , and $30 \mathrm{mg}$ ) in combination with 1.0 or $1.3 \mathrm{mg} / \mathrm{m}^{2}$ bortezomib. In the dose-expansion phase, $20 \mathrm{mg}$ panobinostat plus $1.3 \mathrm{mg} / \mathrm{m}^{2}$ bortezomib was used in the absence (cycle 1 , 
Table 1 Patient characteristics and baseline demographics for B2207 and PANORAMA-1 studies

\begin{tabular}{lll}
\hline Demographic or clinical characteristics & $\begin{array}{l}\text { B2207 (dose-expansion phase) } \\
\text { PAN+BTZ+Dex } \\
N=15\end{array}$ & $\begin{array}{l}\text { PANORAMA-1 (Japan subset) } \\
\text { PAN+BTZ+Dex } \\
N=18\end{array}$ \\
\hline $\begin{array}{l}\text { Median age in years (range) } \\
\text { ECOG PS }\end{array}$ & $62(48-71)$ & $63.5(41-75)$ \\
$0 n(\%)$ & $12(80 \%)$ & $13(72.2 \%)$ \\
$1 n(\%)$ & $3(20 \%)$ & $5(27.8 \%)$ \\
Prior therapies median (range) & $2(1-7)$ & $2(1-3)$ \\
Prior therapy & & $9(50 \%)$ \\
Prior BTZ, $n(\%)$ & $11(73.3 \%)$ & NA \\
Refractory to BTZ, $n(\%)$ & $4(26.7 \%)$ & $2(11.1 \%)$ \\
Prior lenalidomide, $n(\%)$ & $7(46.7 \%)$ & $3(16.7 \%)$ \\
Prior thalidomide, $n(\%)$ & $5(33.3 \%)$ & $16(88.9 \%)$ \\
Prior melphalan, $n(\%)$ & $1(6.7 \%)$ & $\mathrm{NA}$ \\
Prior ASCT, $n(\%)$ & $14(93.3 \%)$ &
\end{tabular}

ASCT autologous stem cell transplant, PAN panobinostat, BTZ bortezomib, Dex dexamethasone, ECOG PS Eastern Cooperative Oncology Group Performance Status score day 8) or presence (cycle 2, day 8) of $20 \mathrm{mg}$ dexamethasone. Pharmacokinetic parameters from B2207 trial are summarized in Table 2. Geometric mean (percent coefficient of variation, $\mathrm{CV}$ ) of panobinostat exposure (AUC0-24) determined in the absence of dexamethasone on cycle 1 day 8 was $61.8(60.9 \%)$ $\mathrm{ng} \mathrm{h} / \mathrm{mL}$ and in the presence of dexamethasone (cycle 2, day 8 ), in the same patient population was 47.5 (76.8\%) $\mathrm{ng} \mathrm{h} / \mathrm{mL}$. The maximum plasma concentration (Cmax) of panobinostat on cycle 1 day 8 in the absence of dexamethasone was 9.5 $(60.4 \%) \mathrm{ng} / \mathrm{mL}$ and in the presence of dexamethasone on cycle 2 , day 8 was $8.1(90.3 \%) \mathrm{ng} / \mathrm{mL}$. In the presence of dexamethasone, an approximately $20 \%$ lower panobinostat exposure was observed, with no apparent difference in the half-life (Table 3).

In single-agent studies $[12,18]$, PK data were taken from patients having an eligible record of multiple oral doses of $20 \mathrm{mg}$ (tiw) panobinostat for comparison. Table 3 shows that the T1/2 (16 h) and Tmax (1-2 h) of panobinostat are the same between historical single-agent trials and the 2 combination trials. However, lower panobinostat exposures (AUC0-24) were seen in both B2207 and PANORAMA-1 compared to single-agent studies. In the B2207 study, the geometric mean of AUC0-24 was 48 (77\%) ng.h/mL, and in PANORAMA-1 study, it was $95(28 \%) \mathrm{ng} \cdot \mathrm{h} / \mathrm{mL}$, with the range of values

Table 2 PK parameters for panobinostat in B2207 trial

\begin{tabular}{lll}
\hline PK parameters & $\begin{array}{l}\text { Cycle 1 day 8 }(n=15) \\
\text { in the absence of Dex }\end{array}$ & $\begin{array}{l}\text { Cycle 2 day 8 }(n=12) \\
\text { in the presence of Dex }\end{array}$ \\
\hline AUC0-24 (ng h/mL) & $61.8(60.9)$ & $47.5(76.8)$ \\
Cmax $(\mathrm{ng} / \mathrm{mL})$ & $9.5(60.4)$ & $8.1(90.3)$ \\
\hline
\end{tabular}

largely overlap (Fig. 2). In single-agent studies, the geometric mean (\% CV) of AUC0-24 was higher at 139 (71\%) $\mathrm{ng} \mathrm{h} / \mathrm{mL}$.

\section{Relationship between panobinostat exposures and response in the $\mathrm{B} 2207$ study}

A summary of efficacy data and PK parameters (AUC0-24 and Cmax) for individual doses of panobinostat is given in Table 4. The rates of ORR and grade 3 or 4 diarrhea and thrombocytopenia are plotted against panobinostat exposures for individual doses of panobinostat in Fig. 3. In the B2207 study, during dose-escalation phase, no dexamethasone was administered to patients. The ORR defined as greater than or equal to partial response (PR) increased with increasing dose of bortezomib (from 1.0 to $1.3 \mathrm{mg} / \mathrm{m}^{2}$ ) and panobinostat (10$30 \mathrm{mg})$. Two $(28.6 \%$ ) patients showed a response of ORR $\geq$ PR at the dose of $20 \mathrm{mg}$ panobinostat and $1 \mathrm{mg} / \mathrm{m}^{2}$ bortezomib, whereas $9(52.9 \%)$ patients achieved $O R R \geq P R$ upon increasing the dose of bortezomib from 1 to $1.3 \mathrm{mg} / \mathrm{m}^{2}$ and keeping panobinostat dose constant at $20 \mathrm{mg}$. The number of patients with $\mathrm{ORR} \geq \mathrm{PR}$ was $11(73.3 \%)$ for the group that received $20 \mathrm{mg}$ dexamethasone in addition to the combination of panobinostat $20 \mathrm{mg}$ and bortezomib $1.3 \mathrm{mg} / \mathrm{m}^{2}$ (Table 4). ORR appears to plateau at the dose of $20 \mathrm{mg}$ (tiw) panobinostat and $1.3 \mathrm{mg} / \mathrm{m}^{2}$ (biw) bortezomib in the doseescalation phase (Fig. 3).

\section{Association of panobinostat exposures with thrombocytopenia in the B2207 study}

During the dose-escalation phase of the B2207 study, incidences of grade 3 or 4 thrombocytopenia were $>80 \%$ (Table 4 and Fig. 3). During the dose-expansion phase (20 mg tiw 
Table 3 Panobinostat PK parameters for single-agent studies vs combination studies

\begin{tabular}{|c|c|c|c|}
\hline PK parameters & $\begin{array}{l}20 \mathrm{mg} \text { PAN single agent } \\
\text { (tiw qw) } \\
N=32\end{array}$ & $\begin{array}{l}\text { B2207 cycle } 2 \text { day } \\
8 \text { PAN }+ \text { BTZ }+ \text { Dex } \\
N=12\end{array}$ & $\begin{array}{l}\text { PANORAMA- } 1 \text { cycle } 1 \text { day } \\
8 \text { PAN+BTZ }+ \text { Dex } \\
N=12\end{array}$ \\
\hline $\operatorname{Tmax}(\mathrm{h})$ & $1(0.5-8)$ & $1(0.5-6.3)$ & $2.02(0.5-4.0)$ \\
\hline $\mathrm{Cmax}(\mathrm{ng} / \mathrm{mL})$ & $21.6(83)$ & $8.1(90.3)$ & $15.3(39.0)$ \\
\hline AUC0-24 (ng h/mL) & $139(71)$ & $47.5(76.8)$ & $95.2(28.4)$ \\
\hline $\mathrm{T} 1 / 2(\mathrm{~h})$ & $16.9(33)$ & $15.9(29.2)$ & $16.7(21.0)$ \\
\hline $\mathrm{CL} / \mathrm{F}(\mathrm{L} / \mathrm{h})$ & $99.8(53)$ & $285.2(79.4)$ & $147.6(30.8)$ \\
\hline $\mathrm{Vz} / \mathrm{F}(\mathrm{L})$ & $2337(53)$ & $6539(81)$ & $3553(32)$ \\
\hline
\end{tabular}

Values are median (range) for Tmax and geometric mean (\% coefficient of variation, $\mathrm{CV}$ ) for all other parameters

$N$ is the number of patients having an eligible record of multiple oral dose, $A U C$ area under the curve, $C L / F$ oral clearance, Cmax maximum plasma concentration, Tmax time to reach Cmax, T1/2 half-life of panobinostat, $V z / F$ apparent volume of distribution

panobinostat and $1.3 \mathrm{mg} / \mathrm{m}^{2}$ biw bortezomib) that used a $2-$ week dosing schedule and 1-week rest with no drugs, the incidence of grade 3 or 4 thrombocytopenia dropped to $66.7 \%$. In the dose-escalation phase, the rate of grade 3 or 4 thrombocytopenia $(85.7 \%$ ) was the same for $10 \mathrm{mg}$ (tiw) and $20 \mathrm{mg}$ (tiw) panobinostat dose at a constant bortezomib dose of $1.0 \mathrm{mg} / \mathrm{m}^{2}$ (biw). At the higher bortezomib dose of $1.3 \mathrm{mg} / \mathrm{m}^{2}$ (biw), the rates of grade 3 or 4 thrombocytopenia were $82.4 \%$ (20 $\mathrm{mg}$ tiw panobinostat), $77.8 \%$ (25 $\mathrm{mg}$ tiw panobinostat), and $100 \%$ (30 mg tiw panobinostat), respectively (Table 4 and Fig. 3).

\section{Association of panobinostat exposures with diarrhea in the B2207 study}

In the B2207 study dose-escalation phase, at the lower bortezomib dose of $1.0 \mathrm{mg} / \mathrm{m}^{2}$ biw and $10 \mathrm{mg}$ or $20 \mathrm{mg}$ tiw panobinostat, no grade 3 or 4 diarrhea was seen (Table 4 and Fig. 3). At the higher bortezomib dose of $1.3 \mathrm{mg} / \mathrm{m}^{2}$ biw, the incidences of grade 3 or 4 diarrhea were $23.5,22.2$, and $14.3 \%$ for the panobinostat doses of 20,25 , and $30 \mathrm{mg}$ tiw, respectively. The absence of grade 3 or 4 diarrhea with $20 \mathrm{mg}$ panobinostat and $1.0 \mathrm{mg} / \mathrm{m}^{2}$ bortezomib $(n=7)$ and their emergence $(23.5 \%)$ with $20 \mathrm{mg}$ panobinostat and $1.3 \mathrm{mg} /$ $\mathrm{m}^{2}$ bortezomib $(n=17)$ implicates bortezomib's contribution

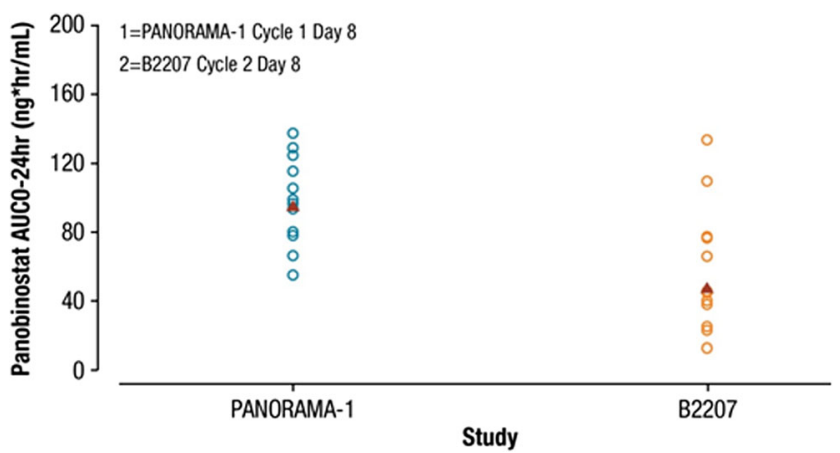

Fig. 2 Exposure comparison between PANORAMA-1 and B2207 patients in this particular AE, even though the observation was based on a very small sample size. During the dose-expansion phase that used 2 weeks on and 1 week off dosing schedule with $1.3 \mathrm{mg} / \mathrm{m}^{2}$ bortezomib, the rate of grade 3 or 4 diarrhea was $20 \%$.

Key grade 3 or 4 AEs from B2207, PANORAMA-1 combination studies and single-agent studies are summarized in Table 5. Though panobinostat exposure is lower in the 2 combination studies, the toxicities are higher. For example, grade 3 or 4 thrombocytopenia occurrence in single-agent studies was about $21 \%$, whereas it was $81 \%$ in the B2207 study and $57 \%$ in the PANORAMA-1 study. Grade 3 or 4 diarrhea was about $3 \%$ in single-agent studies, whereas it was $16 \%$ in the B2207 study and $26 \%$ in the PANORAMA-1 study. The difference in the rates of AEs in the combination studies compared to single-agent studies could be attributed to overlapping toxicities with bortezomib (Table 5).

\section{Discussion}

Three different analyses of panobinostat exposure-response derived from 2 clinical trials were carried out. Initially, the

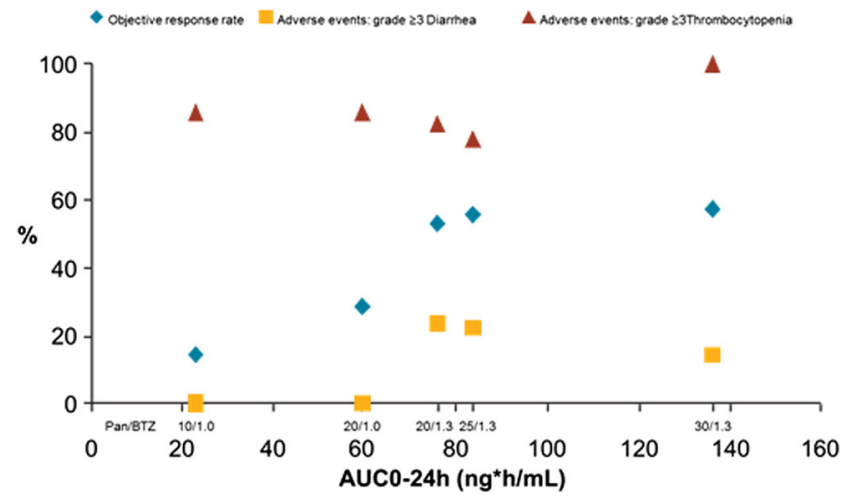

Fig. 3 Exposure-response relationship - B2207 
Table 4 Summary of data on efficacy, exposure, and grade 3 or 4 adverse events (thrombocytopenia and diarrhea) in the B2207 study

\begin{tabular}{|c|c|c|c|c|c|c|}
\hline \multirow[t]{2}{*}{ Efficacy } & \multicolumn{5}{|c|}{ Dose-escalation phase without Dex; PAN given thrice weekly } & \multirow{2}{*}{$\begin{array}{l}\text { Dose expansion } \\
\text { PAN } 20 \mathrm{mg} \\
(2 \text { weeks on } / 1 \text { week off }) \\
+\mathrm{BTZ} 1.3 \mathrm{mg} / \\
\mathrm{m}^{2}+\mathrm{D} \times 20 \mathrm{mg} \\
N=15\end{array}$} \\
\hline & $\begin{array}{l}\text { PAN } \\
10 \mathrm{mg}+\mathrm{BTZ} \\
1.0 \mathrm{mg} / \mathrm{m}^{2} \\
N=7\end{array}$ & $\begin{array}{l}\text { PAN } 20 \mathrm{mg}+\mathrm{BTZ} \\
1.0 \\
\mathrm{mg} / \mathrm{m}^{2} \\
N=7\end{array}$ & $\begin{array}{l}\mathrm{PAN} 20 \mathrm{mg}+\mathrm{BTZ} \\
1.3 \\
\mathrm{mg} / \mathrm{m}^{2} \\
N=17\end{array}$ & $\begin{array}{l}\mathrm{PAN} 30 \mathrm{mg}+\mathrm{BTZ} \\
1.3 \\
\mathrm{mg} / \mathrm{m}^{2} \\
N=7\end{array}$ & $\begin{array}{l}\mathrm{PAN} 25 \mathrm{mg}+\mathrm{BTZ} \\
1.3 \\
\mathrm{mg} / \mathrm{m}^{2} \\
N=9\end{array}$ & \\
\hline $\begin{array}{l}\text { AUC0-24 }(\mathrm{ng} \mathrm{h} / \mathrm{mL}) \\
\text { cycle } 1 \text { day } 8\end{array}$ & $24.1(33.0)$ & $87.5(100.2)$ & $89.1(58.8)$ & $102.8(45.0)$ & $106.4(31.6)$ & $61.8(60.9)$ \\
\hline $\begin{array}{l}\text { Cmax }(\mathrm{ng} / \mathrm{mL}) \\
\text { cycle } 1 \text { day } 8\end{array}$ & $3.5(10.8)$ & $10.8(125.5)$ & $15.8(63.2)$ & $14.5(74.8)$ & $18.0(47.6)$ & $9.5(60.4)$ \\
\hline $\begin{array}{l}\text { Grade } 3 / 4 \\
\text { thrombocytopenia, } \\
\quad n(\%)\end{array}$ & $6(85.7)$ & $6(85.7)$ & $14(82.4)$ & $7(100)$ & $7(77.8)$ & $10(66.7)$ \\
\hline $\begin{array}{l}\text { ORR n }(\%) \text { and } 95 \% \\
\quad \text { CI }\end{array}$ & $\begin{array}{l}1(14.3) \\
{[0.4,57.9]}\end{array}$ & $\begin{array}{l}2(28.6) \\
{[3.7,71]}\end{array}$ & $\begin{array}{l}9(52.9) \\
{[27.8,77.0]}\end{array}$ & $\begin{array}{l}4(57.1) \\
{[18.4,90.1]}\end{array}$ & $\begin{array}{l}5(55.6) \\
{[21.2,86.3]}\end{array}$ & $\begin{array}{l}11(73.3) \\
{[44.9,92.2]}\end{array}$ \\
\hline $\begin{array}{l}\text { Grade } 3 / 4 \text {, diarrhea, } \\
\quad n(\%)\end{array}$ & 0 & 0 & $4(23.5)$ & $1(14.3)$ & $2(22.2)$ & $3(20.0)$ \\
\hline
\end{tabular}

Values are given as geometric mean $(\% \mathrm{CV})$ for AUC0-24 and Cmax

$O R R$ objective response rate

effect of $20 \mathrm{mg}$ dexamethasone on panobinostat exposure was analyzed. Next, the association of panobinostat exposure to rate of response was assessed, and finally, the association of panobinostat exposure to rates of key AEs was determined.

\section{Dexamethasone effect}

A prior study in healthy volunteers showed that $8 \mathrm{mg}$ oral dexamethasone given twice daily for 5 days caused an increase in CYP3A4 activity by approximately $25 \%$ [20]. Isolated hepatocyte cultures treated with increasing concentrations of dexamethasone $(2-250 \mu \mathrm{M})$ showed an increase of CYP3A4 activity from 1.7 to 6.9 -fold [20]. Another study in

Table 5 Selected grade 3 or 4 adverse events from single-agent studies (pooled patient population) vs B2207 and PANORAMA-1 combination trials

\begin{tabular}{|c|c|c|c|}
\hline $\begin{array}{l}\text { Preferred term } \\
\text { Adverse events }\end{array}$ & $\begin{array}{l}20 \mathrm{mg} \\
\text { PAN } \\
(\text { tiw qw) } \\
(N=309) \\
\mathrm{n}(\%)\end{array}$ & $\begin{array}{l}\text { B2207 All Patients } \\
(10-30 \mathrm{mg} \\
\text { PAN })+1.0 \text { or } \\
1.3 \mathrm{mg} / \mathrm{m}^{2} \\
\text { BTZ dose } \\
(N=62) n(\%)\end{array}$ & $\begin{array}{l}\text { PANORAMA-1 } \\
20 \mathrm{mg} \\
\text { PAN }+1.3 \mathrm{mg} / \mathrm{m}_{2} \\
\text { BTZ }+20 \mathrm{mg} \\
\text { Dex }(N=381) n \\
(\%)\end{array}$ \\
\hline Anemia & $29(9)$ & $11(18)$ & $63(17)$ \\
\hline Neutropenia & $42(14)$ & $17(27)$ & $92(24)$ \\
\hline Thrombocytopenia & $66(21)$ & $50(81)$ & $217(57)$ \\
\hline Diarrhea & $10(3)$ & $10(16)$ & $97(26)$ \\
\hline Nausea & $6(2)$ & 0 & $21(6)$ \\
\hline Vomiting & $4(1)$ & $3(5)$ & $28(7)$ \\
\hline Fatigue & $13(4)$ & $7(11)$ & $65(17)$ \\
\hline
\end{tabular}

primary human hepatocytes in culture showed a biphasic induction of CYP3A4 mRNA due to dexamethasone [21]. At low concentrations (below $100 \mathrm{nM}$ ), dexamethasone induces the nuclear protein pregnane $\mathrm{X}$ receptor expression, and this in turn transactivates CYP3A4 mRNA. At higher concentrations (up to $100 \mu \mathrm{M}$ ), dexamethasone directly activates the pregnane $\mathrm{X}$ receptor, with a concurrent increase in CYP3A4 mRNA [21]. This is represented in Fig. 4 (adapted with permission). At the $20 \mathrm{mg}$ oral dose of dexamethasone used in the B2207 study, the projected Cmax for dexamethasone is approximately $30 \mathrm{nM}$. Another pharmacokinetic study using $20 \mathrm{mg}$ panobinostat in combination with $25 \mathrm{mg}$ lenalidomide and $40 \mathrm{mg}$ dexamethasone (day 1 through day 4) showed a further decrease of approximately $60 \%$ in PAN exposure compared to historical single-agent data (unpublished data). Since the fraction of panobinostat metabolized through

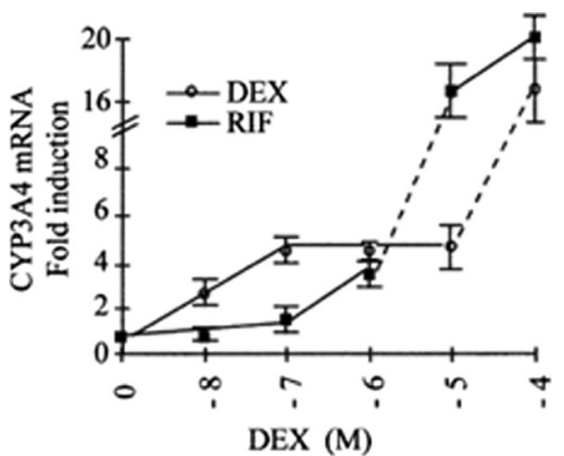

Fig. 4 Biphasic induction of CYP3A4 by dexamethasone. CYP3A4 cytochrome $\mathrm{P} 450$, isoform $3 \mathrm{~A} 4, D E X$ dexamethasone, $R I F$ rifampicin a linear inducer of CYP3A4. Fig. 4 is adapted with permission from Pascussi, JM, et al. (2001) Eur J Biochem 268:6346-6358 
CYP3A is approximately $40 \%$ [10], it is susceptible to inducers of CYP enzymes including dexamethasone. The reduction of panobinostat plasma exposure in combination with dexamethasone confirmed this hypothesis [10].

In the current study, both the combination trials (B2207 and PANORAMA-1) reported lower levels of panobinostat plasma exposure than historical single-agent studies through reduced bioavailability that should be the result of increased first-pass metabolism. Thus, drug-drug interaction with dexamethasone needs to be considered for drugs whose major metabolic pathways involve cytochrome P450 enzymes in clinical trials to avoid exposing patients to subtherapeutic doses since dexamethasone is the backbone therapy in many combinations for multiple myeloma.

\section{Exposure-response analysis}

In the dose escalation part of the B2207 trial, the ORR increased with the increase in bortezomib or panobinostat exposure. Maximum ORR for panobinostat/bortezomib combination $(77.3 \%)$ was achieved upon addition of dexamethasone in the dose-expansion phase. This was in spite of a change in dosing schedule ( 2 weeks on and 1 week off).

It is worth noting that ORR-AUC relationship in the escalation phase of B2207 trial appears to follow a sigmoidal Emax curve. However, there was an approximately $20 \%$ increase in ORR when $20 \mathrm{mg}$ panobinostat was combined with $1.3 \mathrm{mg} / \mathrm{m}^{2}$ bortezomib, instead of $1.0 \mathrm{mg} / \mathrm{m}^{2}$ (Fig. 3). A lower dose of panobinostat $(10 \mathrm{mg})$ with $1.3 \mathrm{mg} / \mathrm{m}^{2}$ of bortezomib is planned to be tested in future trials to see if it could increase the response as the data suggests. The dose of $10 \mathrm{mg}$ panobinostat administered tiw in combination with $1.3 \mathrm{mg} /$ $\mathrm{m}^{2}$ bortezomib may provide a unique balance between efficacy and toxicity.

\section{Analysis of exposure and key toxicities}

Thrombocytopenia is a known toxicity of most pan-histone deacetylase inhibitors and may compromise the options for combination therapies in cancer patients. In the 2 combination trials, the dose of bortezomib impacts the rate of severe thrombocytopenia. In the PANORAMA-1 trial, as subset analysis of 102 patients who completed both treatment phases of panobinostat plus bortezomib plus dexamethasone therapy, the occurrence of grade $\geq 3$ thrombocytopenia reduced from $47 \%$ in treatment phase 1 (that used twice weekly bortezomib dose), to $6 \%$ in treatment phase 2 (that used once weekly bortezomib dose) [22]. An earlier dose-escalation study of panobinostat alone in patients with advanced hematologic malignancies reported $55 \%$ grade $\geq 3$ thrombocytopenia [12]. Recent data suggest that thrombocytopenia may be a downstream event of histone acetylase inhibition at bone marrow
[23]. Thus, thrombocytopenia may be used as a biomarker for target inhibition and dose/regimen optimization.

In patients treated with bortezomib alone, data indicate that incidences of diarrhea were sensitive to bortezomib Cmax. An analysis by Moreau et al. of IV vs subcutaneous (SC) treatment of single-agent bortezomib in patients with multiple myeloma showed that diarrhea is sensitive to bortezomib Cmax [24]. Patients treated with $1.3 \mathrm{mg} / \mathrm{m}^{2} \mathrm{SC}$ bortezomib had a lower mean (SD) Cmax 20.4 (8.87)ng/mL, and $2 \%$ grade $\geq 3$ diarrhea, whereas patients treated with $1.3 \mathrm{mg} / \mathrm{m}^{2}$ IV bortezomib had higher mean (SD) Cmax 223 (101)ng/mL, and $5 \%$ grade $\geq 3$ diarrhea [24]. Diarrhea is one of the overlapping toxicities between bortezomib and panobinostat and is sensitive to bortezomib exposure. Decrease in incidences of diarrhea was seen in the PANORAMA-1 trial upon reducing bortezomib dose to once weekly schedule [25]. Thus, future clinical management of key AEs may be facilitated by dose adjustments and dose reductions.

This study summarizes key analyses of panobinostat pharmacokinetics that will be useful in the treatment of patients with relapsed and refractory multiple myeloma. To date, pharmacokinetics of panobinostat in combination with bortezomib and dexamethasone is very limited, and exposure-response relationship of panobinostat in this combination has not been published. Given the constrains of limited exposure, this study attempted to demonstrate that dexamethasone, which is the backbone of most therapeutic regimens for multiple myeloma, reduces the plasma concentration of panobinostat, $40 \%$ of which is metabolized by CYP 3A4 enzyme. An alternative regimen of once weekly bortezomib is being increasingly used in clinical practice and, at present, represents the standard schedule recommended for elderly patients leading to corresponding change in dexamethasone dose and schedule. Characterization of panobinostat PK in such combinations will be necessary to enable the establishment of exposure-response correlation and provide clinical guideline on its use. This study highlights the importance of understanding drug-drug interactions in combination therapy regimens. Early considerations to exposure response relationships would aid the design of pivotal phase 3 trials.

Acknowledgments The study was funded by Novartis Pharmaceuticals Corporation. We thank Sujata Swaminathan (Novartis Healthcare Pvt. Ltd., Hyderabad, India) for editorial and writing support.

Author contributions All authors participated in study design, data analysis, and drafting of manuscript content. Dr. Y. Kuroda, Dr. H. Shibayama, Dr. M. Hino, and Dr. K. Suzuki are principal investigators who contributed the data collected from the Japanese subgroup of patients as a part of the PANORAMA-1 clinical trial. All authors reviewed and approved the manuscript.

\section{Compliance with ethical standards}

Conflict of interest Dr. S Mu, Dr. E Waldron, Dr. L Rong, Dr. C Corrado, and Dr. F Binlich are employees of Novartis. Dr. H Shibayama had received honorarium/grants from Takeda, Novartis, Janessen, and 
Celgene. Dr. M Hino had received research fund from Novartis. Dr. Y. Kuroda and Dr. K Suzuki do not have any potential conflict of interest.

Open Access This article is distributed under the terms of the Creative Commons Attribution 4.0 International License (http:// creativecommons.org/licenses/by/4.0/), which permits unrestricted use, distribution, and reproduction in any medium, provided you give appropriate credit to the original author(s) and the source, provide a link to the Creative Commons license, and indicate if changes were made.

\section{References}

1. Andreu-Vieyra CV, Berenson JR (2014) The potential of panobinostat as a treatment option in patients with relapsed and refractory multiple myeloma. Ther Adv Hematol 5(6):197-210. doi:10.1177/2040620714552614

2. Libby EN, Becker PS, Burwick N, Green DJ, Holmberg L, Bensinger WI (2015) Panobinostat: a review of trial results and future prospects in multiple myeloma. Expert Rev Hematol 8(1): 9-18. doi:10.1586/17474086.2015.983065

3. Atadja P (2009) Development of the pan-DAC inhibitor panobinostat (LBH589): successes and challenges. Cancer Lett 280(2):233-241. doi:10.1016/j.canlet.2009.02.019

4. Anne M, Sammartino D, Barginear MF, Budman D (2013) Profile of panobinostat and its potential for treatment in solid tumors: an update. Oncol Targets Ther 6:1613-1624. doi:10.2147/OTT. S30773

5. Richardson PG, Mitsiades CS, Laubach JP, Hajek R, Spicka I, Dimopoulos MA, Moreau P, Siegel DS, Jagannath S, Anderson KC (2013) Preclinical data and early clinical experience supporting the use of histone deacetylase inhibitors in multiple myeloma. Leuk Res 37(7):829-837. doi:10.1016/j.leukres.2013.03.006

6. Stessman HA, Baughn LB, Sarver A, Xia T, Deshpande R, Mansoor A, Walsh SA, Sunderland JJ, Dolloff NG, Linden MA, Zhan F, Janz S, Myers CL, Van Ness BG (2013) Profiling bortezomib resistance identifies secondary therapies in a mouse myeloma model. Mol Cancer Ther 12(6):1140-1150. doi:10. 1158/1535-7163.mct-12-1151

7. San-Miguel JF, Hungria VT, Yoon SS, Beksac M, Dimopoulos MA, Elghandour A, Jedrzejczak WW, Gunther A, Nakorn TN, Siritanaratkul N, Corradini $P$, Chuncharunee S, Lee JJ, Schlossman RL, Shelekhova T, Yong K, Tan D, Numbenjapon T, Cavenagh JD, Hou J, LeBlanc R, Nahi H, Qiu L, Salwender H, Pulini S, Moreau P, Warzocha K, White D, Blade J, Chen W, de la Rubia J, Gimsing P, Lonial S, Kaufman JL, Ocio EM, Veskovski L, Sohn SK, Wang MC, Lee JH, Einsele H, Sopala M, Corrado C, Bengoudifa BR, Binlich F, Richardson PG (2014) Panobinostat plus bortezomib and dexamethasone versus placebo plus bortezomib and dexamethasone in patients with relapsed or relapsed and refractory multiple myeloma: a multicentre, randomised, double-blind phase 3 trial. Lancet Oncol 15(11):1195-1206. doi:10. 1016/S1470-2045(14)70440-1

8. San-Miguel JF, Richardson PG, Gunther A, Sezer O, Siegel D, Blade J, LeBlanc R, Sutherland H, Sopala M, Mishra KK, Mu S, Bourquelot PM, Victoria Mateos M, Anderson KC (2013) Phase Ib study of panobinostat and bortezomib in relapsed or relapsed and refractory multiple myeloma. J Clin Oncol 31(29):3696-3703. doi: 10.1200/JCO.2012.46.7068

9. Sharma S, Beck J, Mita M, Paul S, Woo MM, Squier M, Gadbaw B, Prince HM (2013) A phase I dose-escalation study of intravenous panobinostat in patients with lymphoma and solid tumors. Invest New Drugs 31(4):974-985. doi:10.1007/s10637-013-9930-2

10. Clive S, Woo MM, Nydam T, Kelly L, Squier M, Kagan M (2012) Characterizing the disposition, metabolism, and excretion of an orally active pan-deacetylase inhibitor, panobinostat, via trace radiolabeled $14 \mathrm{C}$ material in advanced cancer patients. Cancer Chemother Pharmacol 70(4):513-522. doi:10.1007/s00280-0121940-9

11. Morita S, Oizumi S, Minami H, Kitagawa K, Komatsu Y, Fujiwara Y, Inada M, Yuki S, Kiyota N, Mitsuma A, Sawaki M, Tanii H, Kimura J, Ando Y (2012) Phase I dose-escalating study of panobinostat (LBH589) administered intravenously to Japanese patients with advanced solid tumors. Invest New Drugs 30(5):1950 1957. doi:10.1007/s10637-011-9751-0

12. DeAngelo DJ, Spencer A, Bhalla KN, Prince HM, Fischer T, Kindler T, Giles FJ, Scott JW, Parker K, Liu A, Woo M, Atadja P, Mishra KK, Ottmann OG (2013) Phase Ia/II, two-arm, open-label, dose-escalation study of oral panobinostat administered via two dosing schedules in patients with advanced hematologic malignancies. Leukemia 27(8):1628-1636. doi:10.1038/leu.2013.38

13. Slingerland M, Hess D, Clive S, Sharma S, Sandstrom P, Loman N, Porro MG, Mu S, Waldron E, Valera SZ, Gelderblom H (2014) A phase I, open-label, multicenter study to evaluate the pharmacokinetics and safety of oral panobinostat in patients with advanced solid tumors and various degrees of hepatic function. Cancer Chemother Pharmacol 74(5):1089-1098. doi:10.1007/s00280014-2594-6

14. Sharma S, Witteveen PO, Lolkema MP, Hess D, Gelderblom H, Hussain SA, Porro MG, Waldron E, Valera SZ, Mu S (2015) A phase I, open-label, multicenter study to evaluate the pharmacokinetics and safety of oral panobinostat in patients with advanced solid tumors and varying degrees of renal function. Cancer Chemother Pharmacol 75(1):87-95. doi:10.1007/s00280-0142612-8

15. Feld R, Woo MM, Leighl N, Shepherd FA, Beck JT, Zhao L, Gazi L, Hengelage T, Porro MG, Nayak A (2013) A clinical investigation of inhibitory effect of panobinostat on CYP2D6 substrate in patients with advanced cancer. Cancer Chemother Pharmacol 72(4):747-755. doi:10.1007/s00280-013-2237-3

16. Hamberg P, Woo MM, Chen LC, Verweij J, Porro MG, Zhao L, Li W, van der Biessen D, Sharma S, Hengelage T, de Jonge M (2011) Effect of ketoconazole-mediated CYP3A4 inhibition on clinical pharmacokinetics of panobinostat (LBH589), an orally active histone deacetylase inhibitor. Cancer Chemother Pharmacol 68(3): 805-813. doi:10.1007/s00280-011-1693-x

17. Shapiro GI, Frank R, Dandamudi UB, Hengelage T, Zhao L, Gazi L, Porro MG, Woo MM, Lewis LD (2012) The effect of food on the bioavailability of panobinostat, an orally active pan-histone deacetylase inhibitor, in patients with advanced cancer. Cancer Chemother Pharmacol 69(2):555-562. doi:10.1007/s00280-0111758-x

18. Fukutomi A, Hatake K, Matsui K, Sakajiri S, Hirashima T, Tanii H, Kobayashi K, Yamamoto N (2012) A phase I study of oral panobinostat (LBH589) in Japanese patients with advanced solid tumors. Invest New Drugs 30(3):1096-1106. doi:10.1007/s10637011-9666-9

19. de Estella-Hermoso MA, Imbuluzqueta I, Campanero MA, Gonzalez D, Vilas-Zornoza A, Agirre X, Lana H, Abizanda G, Prosper F (2011) Development and validation of ultra high performance liquid chromatography-mass spectrometry method for LBH589 in mouse plasma and tissues. J Chromatogr B Analyt Technol Biomed Life Sci 879:3490-3496

20. McCune JS, Hawke RL, LeCluyse EL, Gillenwater HH, Hamilton G, Ritchie J, Lindley C (2000) In vivo and in vitro induction of human cytochrome P4503A4 by dexamethasone. Clin Pharmacol Ther 68(4):356-366. doi:10.1067/mcp.2000.110215 
21. Pascussi JM, Drocourt L, Gerbal-Chaloin S, Fabre JM, Maurel P, Vilarem MJ (2001) Dual effect of dexamethasone on CYP3A4 gene expression in human hepatocytes. Sequential role of glucocorticoid receptor and pregnane X receptor. Eur J Biochem 268(24):63466358

22. San Miguel J, Hungria VT, Yoon S-S, Beksac M, Dimopoulos MA, Elghandour A, Jedrzejczak WW, Guenther A, Na Nakorn T, Siritanaratkul N, Schlossman RL, Hou J, Moreau P, Lonial S, Lee J-H, Einsele H, Salwender H, Sopala M, Redhu S, Paul S, Corrado C, Binlich F, Richardson PG (2014) Efficacy and safety based on duration of treatment of panobinostat plus bortezomib and dexamethasone in patients with relapsed or relapsed and refractory multiple myeloma in the Phase 3 Panorama 1 Study. ASH Annual Meeting, Blood,124: Abstract474.

23. Iancu-Rubin C, Gajzer D, Mosoyan G, Feller F, Mascarenhas J, Hoffman R (2012) Panobinostat (LBH589)-induced acetylation of tubulin impairs megakaryocyte maturation and platelet formation. Exp Hematol 40(7):564-574. doi:10.1016/j.exphem.2012.02.004

24. Moreau P, Pylypenko H, Grosicki S, Karamanesht I, Leleu X, Grishunina M, Rekhtman G, Masliak Z, Robak T,
Shubina A, Arnulf B, Kropff M, Cavet J, Esseltine DL, Feng H, Girgis S, van de Velde H, Deraedt W, Harousseau JL (2011) Subcutaneous versus intravenous administration of bortezomib in patients with relapsed multiple myeloma: a randomised, phase 3, non-inferiority study. Lancet Oncol 12(5):431-440. doi:10.1016/S1470-2045(11)70081-X

25. Richardson PG, Hungria VTM, Yoon S-S, Beksac M, Dimopoulos MA, Elghandour A, Jedrzejczak WW, Guenther A, Na Nakorn T, Siritanaratkul N, Schlossman RL, Hou J, Moreau P, Lonial S, Lee JH, Einsele H, Salwender H, Sopala M, Panneerselvam A, Redhu S, Corrado C, Binlich F, San Miguel JF (2014) Characterization of the incidence and management of gastrointestinal toxicity in the Phase 3 Panorama 1 Study of Panobinostat Plus Bortezomib and Dexamethasone Versus Placebo Plus Bortezomib and Dexamethasone in Patients with Relapsed or Relapsed and Refractory Multiple Myeloma. ASH Annual Meeting Blood 124: Abstract 2120. 